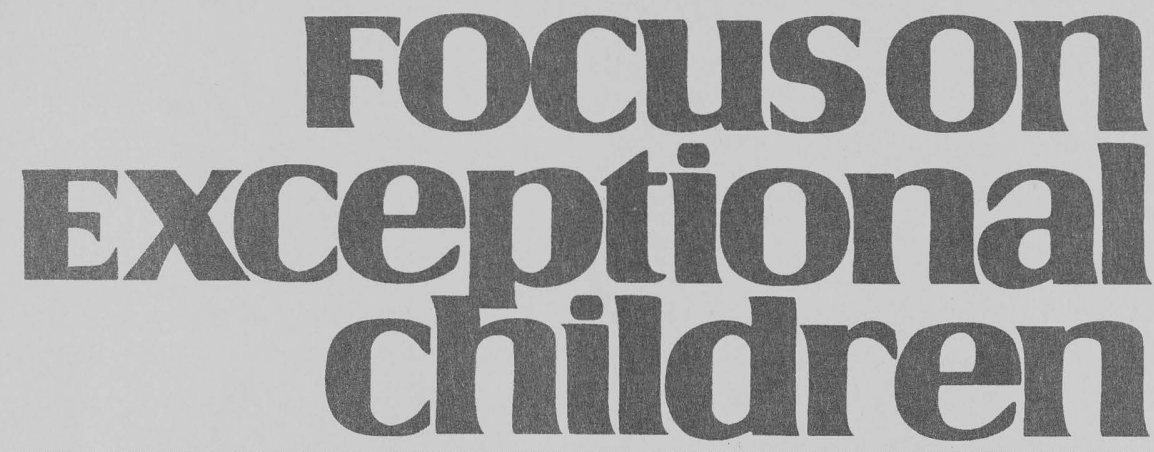

\title{
Planning the IEP for Students With Emotional and Behavioral Disorders
}

\author{
Beverley H. Johns, E. Paula Crowley, and Eleanor Guetzloe
}

The IEP is the driving force in planning an effective educational program for the student. Wood (1992) calls the IEP a "road map for instruction" (p. 11). The 1996 report from the Wingspread Conference on Accountability in Special Education called the IEP the "heart of the special education system" (National Association of State Directors of Special Education, p. 1). It is a safeguard for students and the students' families-it is the document that ensures that children receive specially designed instruction to meet their individual needs.

The Wingspread conference called the IEP both a process and a document. The process involves all of the individual planning steps taken by the team of individuals as they determine an appropriate educational program based on assessment, eligibility, and needs of the student. The document is the concrete confirmation of the decisions reached by the team. The IEP personalizes education by motivating the system to face the need for accommodations to assure that the student with individualized needs has an equal opportunity to education.

A number of revisions to the IEP process, designed to strengthen its role, were made in the Individuals with Disabilities Education Act of 1997 (IDEA 97) and its accompanying regulations. A teacher should not put the IEP in the drawer and forget it until it is time for the annual review; a new requirement assures that parents are updated on a regular basis (at the same time as report cards are issued) on the progress of the student toward that student's goals and objectives (or benchmarks).

\section{KEY COMPONENTS OF THE IEP}

\section{Description of Present Levels of Performance}

This statement of the child's present levels of educational performance must include how the child's disability affects the child's involvement and progress in the general curriculum. Section 300.347 of the regulations defines the general curriculum as the same curriculum as that for nondisabled children. What are the deficit areas of the student? What are the strengths of the student upon which we can build success? Often, IEPs focus too

Beverley H. Johns is with the Garrison Alternative School, Jacksonville, Illinois; E. Paula Crowley is with Illinois State University; and Eleanor Guetzloe is with the University of South Florida, St. Petersburg, Florida. The article is adapted from material in Effective Curriculum for Students With Emotional and Behavioral Disorders, copyright 2002 by Love Publishing Company. 
heavily on deficits-what the student cannot do. This focus is discouraging to the student, the parent, and the teacher. Although it is important for us to outline the deficits so we know specifically what to do for the student, we must also keep strengths in mind so that the majority of each day is spent in providing successful experiences for the student.

For the student with $\mathrm{E} / \mathrm{BD}$, the description of present levels of performance must include not only academic issues but also behavioral issues. For instance, the student with $\mathrm{E} / \mathrm{BD}$ may engage in verbal aggression. The present level of performance must detail a description of the intensity, duration, and frequency of the verbal aggression. Consequently, a functional assessment of the behavior is a must in delineating the present levels of performance. In order to decrease verbal aggression, personnel must teach the student anger control and conflict resolution skills.

\section{Goals and Objectives (or Benchmarks)}

Goals and objectives should be based on present levels of performance: Where does the student need assistance based on the present levels of performance? IDEA 97 requires a

\section{Focuson
Exceptional
children}

ISSN 0015-511X

FOCUS ON EXCEPTIONAL CHILDREN (USPS 203-360) is published monthly except June, July, and August as a service to teachers, special educators, curriculum specialists, administrators, and those concerned with the special education of exceptional children. This publication is annotated and indexed by the ERIC Clearinghouse on Handicapped and Gifted children for publication in the monthly Current Index to Journals in Education (CIJE) and the quarterly index, Exceptional Children Education Resources (ECER). The full text of Focus on Exceptional Children is also available in the electronic versions of the Education Index. It is also available in microfilm from Xerox University Microfilms, Ann Arbor, MI. Subscription rates: Individual, $\$ 36$ per year; institutions, $\$ 48$ per year. Copyright (C) 2002, Love Publishing Company. All rights reserved. Reproduction in whole or part without written permission is prohibited. Printed in the United States of America. Periodical postage is paid at Denver, Colorado. POSTMASTER: Send address changes to:

$$
\begin{gathered}
\text { Love Publishing Company } \\
\text { Executive and Editorial Office } \\
\text { P.O. Box } 22353 \\
\text { Denver, Colorado } 80222 \\
\text { Telephone (303) } 221-7333
\end{gathered}
$$
Karen Harris
University of Maryland
Thomas Skrtic University of Kansas
James Shriner
University of Illinois
Erica J. Lawrence Editor
Stanley F. Love Publisher

statement of measurable annual goals, including benchmarks or short-term objectives, related to meeting the child's needs.

Appendix A to Section 300-"Notice of interpretation"clarifies the difference between short-term instructional objectives and benchmarks. Short-term instructional objectives break down the skills described in the annual goal into discrete components. Benchmarks describe the amount of progress the child is expected to make within specified segments of the year. Benchmarks establish expected performance levels that allow for regular checks of progress that coincide with the reporting periods for informing parents of progress.

The appendix also points out that annual goals are not needed for each area of the general curriculum if the child's disability does not affect the ability to progress in that area. For the student who needs modifications or accommodations to be successful in a specific area of the general curriculum, the specific modifications or accommodations must be delineated on the student's IEP.

\section{Specification of the Amount and Type of Special Education and Related Services}

Where and how can the goals and objectives be met? The date by which the services will be convened should be part of this component.

The least restrictive environment must be addressed in this portion of the IEP. In determining the least restrictive environment, the IEP team should use the criteria delineated in Sacramento City Unified School District Board of Education v. Rachel Holland (1994).

1. Will the student derive educational benefit from the placement? Can the IEP goals be implemented in the placement chosen?

2. What are the noneducational benefits to the student? The examples used in this case were improved selfconfidence and new friendships, and excitement about learning.

3. Is there detriment because the child is disruptive, distracting, or unruly, and would the child take up so much of the teacher's time that the other students would suffer from lack of attention?

4. What is the cost of the placement? Will the placement burden the District's funds or adversely affect services available to other children?

\section{Evaluation Procedures and Schedules}

How often will the goals and objectives be reviewed? These procedures and schedules should be outlined at the time of the IEP. IDEA 97 mandates that the progress of the student toward the goals and objectives of the IEP must be reported to the parent at the same time as report cards are issued for all students. 


\section{Transition Services}

According to IDEA 97, transition services must be included in all IEPs when the student reaches the age of 14 . Beginning at that age, and updated annually, there must be a statement of the transition service needs of the child under the applicable components of the child's IEP that focus on the child's course of study (such as participation in advanced placement courses or a vocational education program). Beginning at the age of 16 (or younger, if determined appropriate by the IEP team), there must be a statement of needed transition services for the child, including, when appropriate, a statement of interagency responsibilities or any needed linkages.

Beginning at least one year before the child reaches the age of majority under the state law, a statement that the child has been informed of his or her rights must be provided.

According to Bateman (1996), transition services are a coordinated set of activities that promote movement from school to postschool activities. The IEP meeting must include a representative of the public agency providing and supervising the transition activities. The student must also be involved.

\section{Consideration of the Evaluation Results}

The results of the initial or most recent evaluation of the child should be considered. This requirement is designed to assure that programming for the student is based on diagnostic information. The heart of special education is the diagnostic-prescriptive approach.

The diagnostic-prescriptive approach is critical for students with emotional and behavioral disorders. If we are unable to meet these children's individual needs, they become frustrated and consequently increase behavioral problems.

\section{Strategies to Address Behavioral Interference of Learning}

In the case of a child whose behavior impedes his or her learning or that of others, the IEP team shall consider, when appropriate, strategies, including positive behavioral interventions and supports, to address that behavior. A common theme throughout IDEA 97 is the use of positive behavioral interventions. We know from a long history of research that a positive focus is the most effective means of changing student behavior. Lewis and Sugai (1999) state that even though peer attention is a powerful motivator for students, teacher attention is also a useful positive reinforcer.

For any student with behavioral concerns, a behavioral intervention plan based on a functional assessment is mandated.

\section{Individual Language Needs}

The IEP team must consider the student's language needs. For children with limited English proficiency, their language needs as they relate to the IEP must be considered. The extent to which a child who has a disability and limited English proficiency receives English instruction or instruction in the child's native language, the extent to which the child will participate in the general curriculum, and the extent to which the child needs English language tutoring must be determined by the member of the IEP team. School districts are required to provide students who have limited English proficiency with alternative language services that enable them to acquire English proficiency.

\section{Students Who Are Visually Impaired}

In the case of a child who is blind or visually impaired, instruction in Braille and the use of Braille must be provided unless the IEP team determines otherwise (designated criteria for that determination are given). The IEP team must make individual determinations for each child who is visually impaired based on relevant evaluation data. The IEP team's determination of whether instruction in Braille is appropriate cannot be based on factors such as the availability of alternative reading media (e.g., large print texts, recorded materials, and computers with speech input).

\section{Individual Communication Needs}

The IEP team must consider the communication needs of the child. In the case of a hearing-impaired student, the IEP team must consider the additional special factors relating to the child's language or communication needs. The range of communication and related needs of hearing-impaired students must be appropriately addressed in evaluation discussions and placement decisions.

\section{Assistive Technology Devices and Services}

The IEP team shall consider whether the child requires assistive technology devices and services. Section 300.308 adds a provision that clarifies that a public agency must permit a child to have access to a school-purchased assistive technology device at home or in another setting if necessary to ensure a free appropriate public education.

\section{Statement of Necessary Individual Accommodations}

There must be a statement of any individual accommodations in the administration of state or districtwide assessments of student achievement that are needed for the child to participate in such assessment.

According to Section 300.138 of the IDEA regulations, each state must demonstrate that children with disabilities are included in general state and districtwide assessment programs, with appropriate accommodations and modifications 
if necessary. States must also develop guidelines for the participation of children with disabilities in alternative assessments for those children who cannot participate in those state and districtwide assessment programs.

\section{Document Portability}

We believe that the IEP should be written so that if a student moves anywhere in the country, the new teacher could pick up the document and be able to plan an effective educational program for the student. In one district, students were required to have an assignment notebook to assist in developing organizational skills. The special education teacher believed that because all of the students in her class used an assignment notebook, there was no reason to put it on the IEP. However, if the student were to move to another district in which assignment notebooks were not used, the new teacher would not know that it was appropriate for the student.

\section{WHO CONSTITUTES THE IEP TEAM}

\section{The Parents of a Child With a Disability}

Each local education agency or state education agency shall ensure that the parents of each child with a disability are members of any group that makes decisions on the educational placement of their child. Section 300.345 of the IDEA 97 regulations outlines the steps that school personnel must take to ensure the parents' opportunity to participate, which include: notifying parents of the meeting early enough to ensure that they will have an opportunity to attend, scheduling the meeting at a mutually agreed on time and place, and giving proper notice that delineates the purpose, time, and location of the meeting. It further states that if neither parent is able to attend, school personnel shall use other methods to ensure participation such as individual or conference phone calls. The section does specify whether an IEP can be held without a parent present. In fact, an IEP meeting can be held without a parent if school personnel are unable to convince the parents that they should attend. The burden of proof is on school personnel, and detailed records to obtain the parent's participation must be kept.

\section{At Least One General Education Teacher of Such Child (if the child is, or may be, participating in the general education environment)}

The general education teacher, as a member of the IEP team, shall, to the extent appropriate, participate in the development of the child's IEP, including the determination of appropriate positive behavioral interventions and strategies and the determination of supplementary aids and services, program modifications, and support for school personnel.

\section{At Least One Special Education Teacher (or, where appropriate, at least one special education provider of such child)}

This requirement can be met by either the child's special education teacher or, as appropriate, another special education provider such as a speech-language pathologist, physical or occupational therapist, or others, if the related service consists of specially designed instruction and is considered special education under the appropriate state's standards. It is the duty of the school district to ensure that all individuals who are necessary to meet the child's unique needs develop the IEP. The special education teacher or provider is supposed to be the person who is, or will be, responsible for implementing the IEP.

A Representative of the Local Education Agency (who is qualified to provide or supervise the provision of specially designed instruction, is knowledgeable about the general curriculum, and is knowledgeable about the availability of resources of the local school district)

The public school can designate another IEP team member as the public agency representative provided that the individual is not serving as the special educator or the general education teacher.

\section{An Individual Who Can Interpret the}

Instructional Implications of Evaluation Results (who may be a member of the team described in the roles of other individuals)

Public schools find it helpful to have a member or members of the eligibility team as part of the IEP team for initial and subsequent meetings to develop a child's IEP. It is critical that there be a strong linkage between the evaluation and the determination of goals and objectives for the student.

\section{At the Discretion of the Parent or the Agency, Other Individuals Who Have Knowledge or Special Expertise Regarding the Child (including related services personnel as appropriate)}

Parents are assisted at their child's IEP meetings if another person can accompany them. Some parents report that they are too nervous to listen and take notes at the same time, so they bring a friend or advocate to take notes for them. Other parents bring a friend for emotional support.

\section{The Child With a Disability, Where Appropriate}

Teachers and parents together should determine whether it is appropriate for the child to attend all or part of the IEP meeting. When transition services are being considered, the student must be invited to attend so that the student has a 
voice in planning for the transition from school to postschool activities. If the student does not attend the IEP meeting, the public agency shall take other steps to ensure that the student's preferences and interests are considered.

\section{ROADBLOCKS TO EFFECTIVE USE OF THE IEP}

\section{Lack of Training and Knowledge}

An IEP that is poorly designed and crafted cannot be used effectively. Teachers may need ongoing training in creating appropriate and effective IEPs. Training must include how to clearly delineate each student's present level of educational performance, how to determine the student's educational needs based on the disability, and how to write goals and objectives that are measurable and reasonably calculated to confer educational benefit. Training must also include how to determine whether a student is able to participate in statewide and local assessments and, if so, what specific accommodations are needed for that assessment and for educational programming throughout the year. A thorough understanding of how to meet all of the requirements of the IEP process is a must for all IEP participants.

There may be times when parents are much better versed in specific methodologies than the educators are. Educators must stay current on methods of instruction through reading and staff development.

\section{Lack of Support in the Implementation of the IEP}

When the special educator attempts to implement the IEP, others in the school may prevent the teacher from doing so. For example, the IEP states that a student identified as $\mathrm{E} / \mathrm{BD}$ (who is in a self-contained $\mathrm{E} / \mathrm{BD}$ classroom) is to be mainstreamed into music class. The music teacher decides that he does not want the student in his class. Another example might involve specific assistive technology that is written into the IEP, and the school district has budget cuts and will not purchase the technology.

\section{Large Caseloads}

Large caseloads sometimes do not give the teacher adequate time to plan and teach. The special education teacher may see students throughout the entire day and not have any planning period. In that case it is very difficult for the teacher to have the time to provide consultation to the classroom teachers who have the student in the general education setting. Because the teacher does not have a break within the school day, the paperwork has to be done on the teacher's own time. This leads to burnout of special educators.

\section{Inadequate or Inaccurate Assessment Information}

An individual test does not mean an evaluation; nor does an assessment by a single individual. Because the diagnostic-prescriptive model is a key component in the delivery of special education services, all evaluations must be multidisciplinary and must be thorough to determine the deficits, strengths, and interests of the student. An evaluation must determine whether a processing deficit is present, at what rate the student learns, and social and emotional factors that may be impacting the child's educational performance.

\section{Pressure Against Individual Plans}

Teachers are sometimes pressured by school district officials to base the IEP on what is available in the district or to ignore IEPs. We have heard numerous stories from teachers who were told that their school district was going to become a "full-inclusion" district, and therefore all students would be in the general classroom all day. The teacher would serve as a consultant to the general education teachers. These districts totally ignored the content of the IEP and ignored the mandated individualization for each child.

Teachers are often pressured to use a standard, computergenerated format for IEPs. Although the computer is an excellent tool for completing paperwork, blanket goals and objectives for all students in the special class are not acceptable. Nevertheless, we have seen situations in which the same goals and objectives were used for all students served by a specific team. Remember, the "I" in IEP stands for "Individual."

\section{Pressure From Classroom Teachers To Provide Tutoring Services Rather Than Specially Designed Instruction}

We have seen this more in secondary programs where a student is mainstreamed in a high school general education class. The classroom teacher refuses to make accommodations and refuses to accept suggestions for making accommodations from the specialist. Instead, the classroom teacher wants the specialist to tutor the student using the same book and keep the student up with the general classroom. The student, however, needs accommodations such as the ability to tape-record the material and to listen to the material multiple times. The student also needs to learn a specific strategy for learning the content and a specific strategy for taking notes during a lecture.

\section{Pressure From Many Sources To Act Unilaterally Rather Than in Accordance With the IEP}

For example: A principal wants a teacher to provide more services for more students, which means it is necessary to decrease the amount of time a particular student receives. Another common example is seen when the student is failing a general education class, and the general education teacher wants the student out of the regular class but doesn't 
want to have a new IEP and wants the special education teacher to add more time without convening a new IEP meeting. The IEP may delineate that the student needs 60 minutes weekly of social work services, but the teacher is told that the social worker is available only one day a week in the school and the student will receive only 30 minutes weekly.

\section{Failure To Recognize Parents as Active Participants in the IEP}

The parents of the student with $\mathrm{E} / \mathrm{BD}$ bring critical information to the table in writing an effective IEP: the student's strengths and weaknesses, the student's likes and dislikes, the student's attitude toward school, and the student's goals after school. School personnel should do whatever is possible to establish the IEP at a mutually agreeable time, set aside enough time for the meeting so the parent does not feel rushed, and make the parent(s) feel comfortable at the IEP meeting.

\section{THE TOP 10 COMMON PROBLEMS IN IEPS}

\section{Failure to separate eligibility from placement.}

Because a student meets eligibility criteria for $\mathrm{E} / \mathrm{BD}$, it cannot automatically be assumed that the student will be placed in a class for students with E/BD. The student's needs could be met in a general education classroom with support services from a behavior management specialist. The process is twofold. The first part is the determination of eligibility for special education. In this process, the team must determine whether the child has a disability and whether that disability has an adverse effect on educational performance. The second part of the process occurs after eligibility is established. At this time, participants must determine the needs of the child based on the evaluation and current levels of performance. Placement decisions are then based on where the child's needs can be most appropriately met according to the least restrictive environment.

\section{Missing critical information.}

An example: The student has failed the vision or hearing screening; the parents have divorced within the last three months; the student has been absent $50 \%$ of the time. Such information is important in gaining an appropriate picture of where the student is and what the needs of that student are.

\section{Failure to provide accurate descriptions of the current levels of educational performance.}

For example: "Johnny has poor attendance." "Billy is physically aggressive." "Mary reads at a third-grade level."
One could ask the following questions: "What is poor attendance?" "What is physical aggression, and how often does it occur?" "Does third-grade level mean word recognition or passage comprehension?"

\section{Failure to clearly identify the special education services and the necessary related services.}

One of the authors was recently reviewing an IEP of a student who had moved into a district. On one page, the IEP said the student was integrated into some general education classes but did not say how many, and the IEP did not delineate how much time during the day the student was in special education. Another common occurrence is that a related service may be listed but the amount of time that the student receives the related services is not listed.

\section{Goals on the IEP not based on deficits described in the present levels of performance and not based on the adverse effects on educational performance.}

As an example, the present levels of performance have identified that the student easily loses his temper and throws books on the floor and knocks over desks twice a day on average. However, when one reviews the student's goals and objectives, there is no goal present to learn anger management skills. Instead, the goals and objectives are related only to the improvement of reading and math skills. Another example is when a student has a significant learning disability in the area of visual memory, and there is no goal to address that deficit area.

\section{Failure to provide enough information in the objectives, including not having an accurate baseline and having unrealistic expectations.}

A student may exhibit difficulty in time on task, and a goal is developed to increase time on task. Yet there is no information on how much time the child currently can stay on task - a baseline has to be established. Or, there may be a baseline that shows that the child is able to stay on a paperand-pencil task in math for two minutes, and the objective specifies that the student will be able to stay on task for 30 minutes. To expect the student to progress from attention to task for 2 minutes to attention to task for 30 minutes may certainly be unrealistic.

\section{Failure to identify reasons for rejection of placement.}

In some IEPs, placement in a general education class is rejected because-it is stated-it is "not appropriate." An explanation should be given. In addition, consideration should be given to how it could be made appropriate for the student. 


\section{IEPs that do not reflect the amount of time spent in special education and general education and what is happening with the student.}

For example: The IEP may state that the student is receiving 50 minutes of resource services daily from the E/BD teacher; however, an investigation of the child's day shows that he or she is receiving those services only every other day. It is also common for an IEP to state that a student is in $\mathrm{E} / \mathrm{BD}$ instructional class all day, when in fact that student is integrated into music, art, PE, and a speech class. The IEP should reflect what is actually happening with the student.

\section{Failure to identify other needs and disabilities that the student may have.}

An example: A student might have an identified learning disability as well as emotional and behavioral disorders. However, there is no mention in the IEP that the student has an auditory-processing deficit that is exhibited when the student is expected to follow an auditory directive from the teacher. The student needs to have a visual cue as well as a verbal direction. One student who had a very slow processing time would take at least one minute to process a request and then perform the task requested. If teachers did not know of this disability or did not address it on the IEP, they might not understand why the student was not doing what was requested of him.

\section{Integration into general education classes not driven by the IEP but by a level system.}

The decision about integrating a student into general education classes must be made by the IEP team, not by a level system.

\section{MAKING THE MOST OF THE IEP}

\section{Evaluation}

The IEP should be based on appropriate assessment information including testing, observation of a student's educational performance, any processing deficit, learning style, and a functional analysis of behavior. It is expected that an evaluation of each student is completed every three years. Additionally, the special education teacher is continually engaged in ongoing assessment through observations, standardized achievement tests, and, for students with $\mathrm{E} / \mathrm{BD}$, an ongoing functional analysis of behavior.

The three-year evaluation is conducted by a multidisciplinary team including at least one teacher or other specialist with knowledge in the area of the suspected disability. Additionally, for students suspected of having a learning disability, the IDEA regulations state:

\begin{abstract}
the child does not have a regular teacher, a regular classroom teacher qualified to teach a child of his or her age, or (3) For a child of less than school age, an individual qualified by the State educational agency to teach a child of his or her age; and (b) At least one person qualified to conduct individual diagnostic examinations of children, such as a school psychologist, speech-language pathologist, or remedial reading teacher. (Federal Register, 34 CFR 300.540)
\end{abstract}

No longer can only one person perform the evaluation and declare that a student is eligible for special education; for the protection of the student it is a team effort.

It is critical for students with E/BD that behavioral observations and evaluations and a functional assessment of behavior are conducted. A functional assessment is defined as a process of identifying personal and environmental events that contribute to the occurrence of target behaviors and assist in organizing the information to select appropriate interventions for the student. The purpose of a functional assessment is threefold: (a) to determine the variables that may be associated with the problem behavior; (b) to identify the function of the problem behavior; and (c) to examine the consequences of the behavior that may be contributing to its maintenance. It is a proactive and positive approach to reduce inappropriate behavior and increase appropriate skill development and certainly increases the likelihood of a positive outcome following intervention efforts.

A simple way to remember how to do a functional assessment is to relate the process to the mnemonic $\mathrm{ABC}$ :
A: Antecedents-what comes before the behavior
B: Behavior-operationally defined
C: Consequences-what comes after the behavior

Once the information is gathered, the evaluator should attempt to determine the purpose that the misbehavior serves. All behavior serves one of these functions:

- Attention-seeking: The child performs the challenging behavior in order to secure or maintain someone's attention.

- Escape: The child performs the challenging behavior when he or she does not want to perform a particular task.

- Tangible: The child exhibits a challenging behavior in order to obtain or keep an object.

- Sensory: The child performs a challenging behavior because of a need for stimulation.

The special educator can then plan an intervention based on this critical information, which provides for the child's needs in a socially appropriate way and for a brief, consistent consequence for the misbehavior. 
Bateman (1996) offers very helpful suggestions to assure an appropriate evaluation. She maintains that it is important to individualize the evaluation and assess the child in all of the areas related to the suspected disability. One standard battery or standard procedure administered to all children is, in her words: "unprofessional and unacceptable, even though too common" (p. 5). She also warns:

Don't rely on any formula or quantitative guideline to determine eligibility. The more elaborate the formula, the sillier it will appear to a judge. The law requires professional judgment be relied on, and sole reliance on any quantitative guideline is prohibited. (p. 6)

\section{What Deficits Interfere With Learning?}

After the evaluation is completed and the levels of performance assessed, deficits for which goals and objectives will need to be written must be identified. An example: Through evaluation and a statement of the present levels of performance, a student has been identified as having difficulty with attention to task. The current performance level is defined as: Attention to task is currently 2 minutes on an independent second-grade level activity. The student is able to do second-grade work. This is a definite deficit that interferes with learning in a second-grade classroom. Based on the knowledge that there is a deficit, a goal and an objective can be written to address it.

For students identified as E/BD, it is critical that specific behavioral problems are described along with their frequency and duration. For instance, the statement "Johnny is physically aggressive" is not enough. What is the teacher's definition of physical aggression? Is it hitting other students in the classroom or on the playground? Is it throwing books? Is it throwing furniture? Definitions of physical aggression vary and it is important to be as specific as possible. It is equally important to note how often physical aggression occurs. Once a month? Once a week? Five times a day?

\section{Writing Appropriate, Meaningful, and Effective Goals and Objectives}

Students must gain meaningful benefit from an IEP. Clearly written goals and objectives can provide us with the information needed to show that benefit. Imagine a student who engages in verbal aggression 10 times a day each time he is given an assignment in the classroom, although the work is at an appropriate level for the student. The verbal aggression is defined as swearing very loudly so that all students in the classroom can hear. That is the present level of performance. The goal: To decrease verbal aggression in the classroom. The objective might be: Given an assignment at the appropriate third-grade level, Johnny will start the assignment, refraining from becoming verbally aggressive (swearing) so that there are no more than 5 such occurrences during any day. As the student progresses, benefit is seen because the number of incidents involving verbal aggression has decreased from 10 to 5 . Needless to say, the teacher should be implementing a behavioral intervention plan to gain this progress.

\section{Determining Appropriate Accommodations and Modifications for the Student}

Section 504 of the Rehabilitation Act of 1973 states that reasonable accommodations must be made for students. Such accommodations are adaptations or adjustments in the classroom that will assist the student in learning skills. The National Information Center for Children and Youth with Disabilities (1996) outlines some sample accommodations. For note-taking, accommodations may include: use of a tape recorder in the class, use of another student's notes, a notetaker, a study guide provided by the teacher, use of a computer or typewriter. Test-taking accommodations may include: extended time on the test, taking the test in a quiet area, having someone read the test to the student, having the student take the test orally. Additional accommodations may include: preferential seating, textbooks-on-tape, extended timelines, and so on.

Accommodations do not modify the same curriculum content. Modifications, however, do change curriculum content. A modification might be to change the number of spelling words a student is required to learn or to utilize a high-interest, low-vocabulary book.

When considering reasonable accommodations, it is important that the student and teachers who will be implementing the accommodations be involved in those decisions. I once attended a staff meeting that concerned a student who had an auditory memory deficit and required repetition of what was said, and he needed to visually see the material to learn it. Most participants wanted to allow the student to use a tape recorder for lecture classes. The student did not want to use a tape recorder because he didn't like to listen to the tape after class. He wanted to learn how to take notes. His desire was an example of information from the IEP driving curriculum and a good example of student self-advocacy. In the same meeting, all teachers were present and all but one had stated they were willing to provide the student with "word banks." One teacher sat quietly throughout the discussion and finally asked: "What is a word bank?" If only one or two of the student's general education teachers attend the meeting, accommodations are recommended, and often, the other teachers are not made aware of these. An effective communication system must be established so that teachers know what accommodations have been recommended. Teachers are often reluctant to make accommodations because they do not know how to do so or do not have the time to make the accommodations. As the 
IEP team develops those accommodations, it is important that teachers be provided the opportunity to receive training in how to make accommodations.

The IEP team must also be cognizant of which accommodations are reasonable and which are not. We have found that unless teachers are involved in the decision-making process, the team might not be able to evaluate an accommodation in terms of what is reasonable in the classroom setting.

\section{Planning an Effective Behavioral Intervention Plan to Meet the Needs of the Student}

A behavioral intervention plan should be based on a functional assessment of the student's behavior, and should be designed to meet the goals and objectives of the student. If the goal for the student is to decrease verbal aggression (defined as swearing at the teacher when given a direction that the student does not want to do), the behavioral intervention plan should be designed to assist the student in reaching that goal. At the same time, the goals and objectives and the behavioral intervention plan should also drive a portion of the student's curriculum. The teacher must teach the student alternative ways to deal with anger other than verbal aggression. (The teaching of social skills will be discussed later.)

\section{Point Systems}

One of the major flaws in classes for children with $\mathrm{E} / \mathrm{BD}$ is the lack of individualization in point systems and level systems. Although these techniques may be key components in operating an effective E/BD classroom, they are often not individualized and not based on the needs identified on the IEP. How will point systems and level systems be implemented and adjusted to the individual needs of the child? Point systems are effective only if they are paired with positive verbal reinforcement. Often teachers become mechanical engineers so busy recording points and charting that they don't make those greatly needed positive comments to the students. The behaviors targeted for the student's point sheet should be based on both the classroom rules and behaviors identified on the student's IEP.

Time intervals should be based on the level of the student. We have seen teachers establish point systems for first graders that provide points once an hour, which is a long time for a young student to wait for feedback. Five or 10 minutes may be a more appropriate interval for young students; 20 or 30 minutes may be appropriate for older students, depending on the student's developmental and social maturity level. I was working with a special education teacher of junior high school students with multiple needs, who I observed were at a social level of about 5 years. They needed frequent positive reinforcement. I worked with the teacher to establish a point system based on 5minute intervals.

If skill deficits are part of the point system, the teacher must provide instruction in those deficit areas. A skill deficit refers to a behavior that the student has not yet learned. A performance deficit is a behavior that is currently exhibited by the student, but not to satisfactory criteria. If the teacher is uncertain if the student has a skill deficit or a performance deficit, he or she should assume it is a skill deficit and teach the skill. Scheuermann and Webber (1996) encourage social skills assessments and observational recordings to determine whether the student has a skill deficit or a performance deficit.

Finally, point systems are based on the premise that beyond positive verbal feedback, the student will receive some other type of positive reinforcement based on the number of points received (such as a tangible item purchased in a "store," free time, movie, and so on). Those reinforcers must be based on the interests and level of the student. The IEP is an excellent vehicle for learning what motivates the student; the parent knows what the student does and does not like and how the student likes to spend his or her free time. Motivators for the student should be identified on the IEP.

\section{Level Systems}

The pitfalls of level systems have been studied by Scheuermann and Webber (1996). They define level systems as consisting of "target academic and social behaviors arranged in a sequential hierarchy of 'levels,' ranging from the most basic skills at the lowest level to the most complex skills at the highest level" (p. 21). There are several problems with level systems. Teachers who plan to implement such systems must be sure that procedural safeguards are followed and the individualized needs of the student are addressed. Level systems should not determine access to general education classes. The law is clear; IEPs determine integration into general education classes-not level systems. Educational placement and access to nondisabled peers should not be used as level-system privileges.

Another problem with level systems is that all students are expected to attain the same behaviors at the same mastery schedule. For instance, the teacher may identify work completion or attention to task as a behavior that must be exhibited to progress in the level system; yet one student has a different skill level and may not be able to attend to a task as long as another student. Although it is appropriate to have some behaviors or expectations on the level system based on the rules of the classroom, it is also important that individual target behaviors be identified through the IEP process. The criteria for progressing through the level system should also be addressed individually. According to Scheuermann and Webber (1996), it is not appropriate to have a policy that 
has all students begin the level system at the lowest level or the middle level or highest level. The decision for the appropriate level for the student should be made by the IEP team.

Additionally, privileges should not be arranged hierarchically, with those most desired available at only the highest levels. If reinforcers are not individualized, school personnel must carefully investigate whether the reinforcers are in fact such for individual students.

Consequences for inappropriate behavior should also be addressed within the context of the IEP. Will the consequence for inappropriate behavior be a drop of level? Scheuermann and Webber (1996) recommend that it should not be. They recommend that consequences for inappropriate behaviors be independent of the level system. In any case, that decision should be made by the IEP team.

As the IEP team determines the individual effectiveness of a level system for a student, the team must determine whether the student is making satisfactory progress through the level system. For example, if the team has determined previously that the student should enter the level system at level 1 and a year later sees that the student has never moved from level 1 , the group must reevaluate whether this system is effective for the student. Are the behavioral expectations appropriate for the student? Has the student been taught the skills to meet the behavioral expectations? What are the reinforcers that the student earns within the level system? Scheuermann and Webber (1996) outline possible reasons for lack of student progress within a level system: The student does not have the necessary prerequisite skills for the expected behaviors identified as targets on the level system; the student does not know how to perform those target behaviors; mastery criteria may not be reasonable and attainable; mastery criteria are not sufficient to ensure that the student really learns the target behaviors; reinforcers are not effective; and consequences for inappropriate behaviors are more appealing than consequences for engaging in the appropriate target behaviors.

Scheuermann and Webber (1996) stress the importance of targeting self-management skills in the level system. It is important to incorporate such skills as self-monitoring, selfevaluation, self-reinforcement, or a combination of the three into the level system. Self-management skills are necessary for generalization of behavior gains and certainly necessary for success in less restrictive environments. Students with E/BD typically do not exhibit such skills; therefore, they should be an integral part of the curriculum for E/BD students.

As teachers evaluate a level system, they should answer the following questions:

- Is integration into general education classes determined by the IEP rather than the level system?

- Is the entry level in the system determined by the IEP committee?
- Is placement on the level system based on current valid assessment?

- Are skill deficits considered when planning the student's level system? Are those skills then taught as part of the curriculum?

- Are advancement criteria appropriate for each student and based on the student's developmental level?

- Is each student's progress on the level system monitored frequently?

- Do behaviors that are addressed in the level system maintain over time and generalize to other environments?

\section{Contracting}

Contracting may also be an effective behavior management technique to be incorporated into the IEP. We recommend contracting as most appropriate for students in fifth grade and above. The length of time of the contract is dependent, as a point system is, on the age and maturity level of the student. The general rule of thumb is to start with a shortterm contract to assure success for the student. When negotiating a contract with a student, the teacher should zero in on one behavior. At one school, I advised that a contract be developed for a student. When I followed up with the school and asked how the contract was progressing, staff members responded that it wasn't working at all. The student's behavior had deteriorated. When I inquired about the details of the contract that had been developed, I was told a list of 12 behaviors had been made that the student was expected to exhibit. I then asked what reward the student would receive for following the contract. The staff stated: "Nothing, she is just supposed to do these things and these are the consequences she will get if she doesn't follow these 12 expectations." Needless to say, this was contracting gone amuck.

A reward for following the behavior expected on the contract should be appropriate for the student. That reward does not have to be a material item, and if it is, it should not be an expensive one. We have found that attention from an adult is a powerful motivator for some students. One student likes to spend time with an adult at the end of every day if she has refrained from verbal aggression and can also earn a soft drink from the teacher if she wears her glasses every day. Consequences for not following the contract should be natural and logical. Johns, Carr, and Hoots (1995) provide a list of natural and logical consequences for inappropriate behavior. The purpose of the contract is to gain ownership from the student to work on the behavior; therefore, it is important for the student, parent, and teacher to sign it. It is also important to provide the student with a daily review of the contract and to post it where the student can see it.

The use of restrictive behavioral intervention must be addressed on the student's IEP. Teachers may not act unilaterally to determine that a restrictive intervention is appropriate 
for a student. Procedures that deny access to education for a portion of the day (such as time-out, in-school suspensions) or procedures that are intrusive in nature, such as the use of physical intervention or a helmet for head-banging, must be specified on the student's IEP. In a videotape, Johns and Carr (1994) outline the legal issues surrounding the use of safe physical intervention. That tape stresses that any such use must be addressed and specified on the student's IEP.

\section{TRANSITION PLANNING}

Students who are above the age of 14 must be involved in their own IEPs to determine an appropriate plan for them to achieve their life goals after the completion of school. Transition planning includes discussing and planning for such areas as the student's employment, postsecondary education, independent living, eligibility for various adult services, community participation, and vocational evaluation. According to Agran (1997), federal law acknowledges that for too long students have had no say in their education and their input, which was long denied, is now valued. The traditionally passive role of the student in educational decision-making is no longer acceptable. Activities must be based on the student's needs, preferences, and interests.

Transition planning provides an excellent opportunity for a student to individually reflect about plans for the future, what the student wants to do, and what types of training or experience the student needs in order to prepare and how the school can help in meeting the student's future goals. Discussion of the student's transition plan will drive the curriculum for the student.

Agran (1997) stresses teaching a strategy to students to prepare them for the transition planning process. That strategy, called IPLAN, includes:

I: Inventory your strengths, weaknesses, goals, and choices for learning

P: Provide your inventory information

L: Listen and respond

A: Ask questions

$\mathrm{N}$ : Name your goals

\section{What Assessments Will Be Conducted to Determine Student Progress?}

Does the district have a districtwide assessment or is there a state-required assessment? Will the student participate in that assessment or will the student be provided with alternate assessment? If the student does participate in the assessment, what accommodations will need to be implemented? There is much discussion about whether identified special education students should participate in local and statewide assessments. While this discussion continues, it is important to remember that deciding if a student should or should not be included in those assessments should be made by the IEP team and should be delineated on the IEP.

\section{In What Least Restrictive Environment Can Specially Designed Instruction Be Provided?}

After goals and objectives have been carefully crafted, the next question is how can those goals and objectives be met? In what setting? Can behaviors be controlled and changed in a general education class? In a resource class? In an instructional program? Or in a specialized setting? Are behavior problems of such a serious nature that the safety of other students is at stake? Can factors in the environment be changed? The school district has to have available a full continuum of alternative placements, including general education classrooms with supplementary aids and services, resource services, special classes, and special schools. When making the placement decisions, consideration must be given to any possible effect on the child or on the quality of the services that he or she needs. Most important, the placement must be based on the individual needs of the child and must be reviewed annually.

\section{PROMOTING PARENT-EDUCATOR PARTNERSHIPS THROUGH THE IEP: TIPS FOR THE EDUCATOR}

Parents are a required and integral part of the IEP process. After all, they live with the child and know more about the child's needs and interests than the educator does. It is therefore critical that the parent be a partner in the IEP process. However, educators often establish roadblocks that prevent parents from being full participants in the process. The following are some helpful hints to assure that the parent feels comfortable in the IEP.

- Hold meetings at a time that is mutually agreeable to all participants.

- Avoid assembly-line IEPs. When teachers schedule eight IEP meetings in the same day and establish a tight time schedule, parents feel rushed and don't feel they can ask the questions they might have.

- Offer coffee or tea at meetings.

- Offer the parent the seat next to the person chairing the meeting. Individuals will look at the person who is chairing the meeting, so parents will also gain from that eye contact.

- Introduce everyone at the meeting and explain their roles.

- Let parents tape-record the meeting if they wish.

- Explain the purpose of the meeting.

- Avoid having the IEP form completed before the meeting. The development of the IEP should be a group process with parent input. 
- Avoid educational jargon.

- Accentuate the child's strengths-review those first. Then discuss deficit areas. No parent wants to hear only negative statements about his or her child.

- Ask for the parents' input throughout the meeting: "Do you also see this behavior at home?" "What does your child like to do in his free time?"

- If the parent makes statements you don't agree with or find offensive, comment first on those statements you agree with and then discuss the points you do not agree with.

- Have parents participate in writing goals for their child. They usually have in mind particular behaviors or skills that they would like to see their child achieve.

\section{REFERENCES}

Agran, M. (1997). Student directed learning: Teaching self-determination skills. Pacific Grove, CA: Brooks/Cole.

Bateman, B. (1996). Better IEPs: How to develop legally correct and educationally useful programs. Longmont, CO: Sopris West.

Federal Register, March 12, 1999 (Volume 64, Number 48). 34 CFR Parts 300 and 303.

Johns, B., Guetzloe, E., Yell, M., Scheuermann, B., Webber, J., Carr, V., \& Smith, C. (1996). Best practices for managing adolescents with emotional/behavioral disorders within the school environment. Reston, VA: Council for Children with Behavioral Disorders.
Johns, B., \& Carr, V. (1994). Safe physical intervention: The Garrison Model for dealing with physical aggression. Video. Garrison School, 936 West Michigan, Jacksonville, IL 62650.

Johns, B., Carr, V., \& Hoots, C. (1995). Reduction of school violence: Alternatives to suspension. Horsham, PA: LRP.

Kirk, S., \& Chalfant, J. C. (1984). Academic and developmental learning disabilities. Denver: Love.

Kovac, M. (1996). A student's guide to the IEP. Washington, DC: National Information Center for Children and Youth with Disabilities.

Lewis, T., \& Sugai, G. (1999). Effective behavior support: A systems approach to proactive schoolwide management. Focus on Exceptional Children, 31(6), 1-24.

Maloney, M., \& Pitasky, V. (1995). The Special Educator 1995 desk book. Horsham, PA: LRP.

National Association of State Directors of Special Education. (1996). Enhancing individual student accountability through the IEP: Report of the Wingspread Conference on accountability in special education. Alexandria, VA: National Association of State Directors of Special Education.

Sacramento City Unified Sch. Dist. Bd. of Educ. v. Rachel H., 20 IDELR 812 (9th Cir. 1994).

Scheuermann, B., \& Webber, J. (1996). Level systems: Problems and solutions. Beyond Behavior, 7(2), 12-17.

Vaughn, S., Bos, C., \& Schumm, J. (1997). Teaching mainstreamed, diverse, and at-risk students in the general education classroom. Boston: Allyn and Bacon.

Wood, J. (1992). Adapting instruction for mainstreamed and at-risk students. New York: Merrill.

20 U.S.C. 1400 et seq. Amendments to the Individuals With Disabilities Education Act.

\section{INDEX ・ Volume 34}

\section{Author Index}

Bogner, Kristen (January 2002)

Cranston-Gingras, Ann (September 2001)

Crowley, E. Paula (May 2002)

Dolezal, Sara (January 2002)

Doyle, Mary Beth (March 2002)

French, Peter (September 2001)

Giangreco, Michael F. (March 2002)

Grigal, Meg (April 2002)

Guetzloe, Eleanor (May 2002)

Jiménez, Robert T. (February 2002)

Johns, Beverley H. (May 2002)

Moon, M. Sherril (April 2002)

Myles, Brenda Smith (November 2001)

Neubert, Debra A. (April 2002)

Paul, James (September 2001)

Pressley, Michael (January 2002)

Raphael, Lisa M. (January 2002)

Roehrig, Alysia (January 2002)

Simpson, Richard L. (November 2001)

Swanson, H. Lee (October 2001)

Whitaker, Susan D. (December 2001)

\section{Chronological Index of Titles}

Ethics and Special Education (September 2001)

Searching for the Best Model for Instructing Students With Learning Disabilities (October 2001)

Effective Practices for Students With Asperger Syndrome (November 2001)

Supporting Beginning Special Education Teachers (December 2001)

Balanced Literacy Instruction (January 2002)

Fostering the Literacy Development of Latino Students (February 2002)

Students With Disabilities and Paraprofessional Supports: Benefits, Balance, and Band-Aids (March 2002)

Post-Secondary Education and Transition Services for Students Ages 18-21 With Significant Disabilities (April 2002)

Planning the IEP for Students With Emotional and Behavioral Disorders (May 2002) 